\title{
Optimal Income Taxation, Outsourcing and Policy Cooperation in a Dynamic Economy
}

\author{
Thomas Aronsson \\ Umeå University, Sweden \\ and \\ Erkki Koskela \\ University of Helsinki and HECER
}

Discussion Paper No. 269

August 2009

ISSN 1795-0562

HECER - Helsinki Center of Economic Research, P.O. Box 17 (Arkadiankatu 7), FI-

00014 University of Helsinki, FINLAND, Tel +358-9-191-28780, Fax +358-9-191-28781, E-mail info-hecer@helsinki.fi, Internet www.hecer.fi 


\title{
Optimal Income Taxation, Outsourcing and Policy Cooperation in a Dynamic Economy*
}

\begin{abstract}
This paper concerns optimal income taxation in a two-country OLG economy, where each country is characterized by asymmetric information between the government and the private sector, and where one of the countries outsources part of its production to the other. In the country whose firms outsource production abroad, the government will respond to outsourcing by implementing a more progressive labor income tax structure and higher marginal income tax rates than it would have done in the absence of outsourcing. The tax policy response by the government in the country that receives foreign production capacity is, in general, ambiguous and depends on a tradeoff between wage-equality and factor income from abroad. By using the non-cooperative Nash equilibrium as a reference case, we also consider how coordinated tax reforms can be designed leading to higher welfare.
\end{abstract}

JEL classification: H21, H25, J31, J62.

Keywords: outsourcing, redistribution, optimal nonlinear taxation, intertemporal model.

Thomas Aronsson

Department of Economics

Umeå University

SE - 90187 Umeå

SWEDEN

e-mail: thomas.aronsson@econ.umu.se
Erkki Koskela

Department of Economics

University of Helsinki

P.O. Box 17 (Arkadiankatu 7)

FI-00014 University of Helsinki

FINLAND

e-mail: erkki.koskela@helsinki.fi

* The authors would like to thank Tomas Sjögren for helpful comments and suggestions. Aronsson would like to thank the Bank of Sweden Tercentenary Foundation, the Swedish Council for Working Life and Social Research and the National Tax Board for research grants. Koskela thanks the Academy of Finland (grant No. 1117698) for financial support and Department of economics, Umeå University, for good hospitality. 


\section{Introduction}

International outsourcing has become an increasingly important business practice, and is meant to imply that firms locate part of their production process in another country. Earlier research shows that wage differentials across countries constitute important driving forces behind this behavior, as the costs will be reduced if part of the production is located to a country with lower wages. ${ }^{1}$ There is also empirical evidence suggesting that international outsourcing of production leads to more wage-inequality in the sense of increasing the skill-premium. ${ }^{2}$ However, despite that international outsourcing may deteriorate the income prospects of the low-skilled in countries that outsource production abroad, and despite that it may cause income redistribution and externalities at the international level, outsourcing has so far received very little attention in the literature on optimal income taxation. Two questions immediately come to mind. First, how would the national government, whose firms outside production abroad and whose objective is based on the domestic welfare, adjust its redistributive tax policy in response to international outsourcing? Second, what is the tax policy response by the government in the country that receives foreign production capacity and is also based on domestic welfare. Third, does this type of outsourcing justify tax policy cooperation at the international level? The present paper attempts to answer these two questions. The main purpose is to analyze how outsourcing affects the optimal income tax structure in a dynamic economy, where we make a distinction between, on the one hand, the country whose firms locate part of their production abroad and, on the other, the host-country that receives foreign production structure with employment opportunities for its own labor force. This also provides a natural framework for studying the international externalities that outsourcing gives rise to and, as a consequence, to analyze the welfare effects of policy cooperation between countries.

1 See, e.g., Amiti and Wei (2005), Rishi and Saxena (2004) and Sinn (2007). At the same time, wage differentials alone may exaggerate the incentives for outsourcing due to a mismatch between technology and the skills of workers in less developed economies; see, e.g., Acemoglu and Zilibotti (2001). For an overview, see Hummels et al. (2001).

2 See, e.g., Feenstra and Hanson (1999, 2003), Hijzen et al. (2005), Hsieh and Woo (2005), Hijzen (2007), Egger and Egger, (2006), Munch and Skaksen (2009), Riley and Young (2007) and Geishecker and Görg (2008). 
To be able to explore the relationship between outsourcing, wage inequality and optimal redistributive taxation, we incorporate outsourcing into a model with two ability-types and asymmetric information between the government and the private sector. Our model is, therefore, an extension of the optimal income tax model with two ability-types developed in its original form by Stern (1982) and Stiglitz (1982), which is by now one of the major workhorses in this area. The tax instruments that each national government has at its disposal are nonlinear taxes of labor income and capital income, respectively. Such a tax system constitutes a reasonably realistic description of the options available for income taxation. It also implies that the appearance of tax distortions at the second best optimum is a consequence of optimization subject to informational limitations only; not any other restriction such as the necessity to raise revenue per se. A similar model was used by Aronsson and Koskela (2009a), although their study is partial in the sense of focusing all attention on the country whose firms outsource production abroad. Furthermore, their study is based on a static model, which does not contain capital income taxation. They show that if the government is able to control the amount of resources spent on outsourcing via a direct tax instrument, then outsourcing will not (by itself) modify the policy rules for marginal labor income taxation. However, if the government lacks a direct instrument for taxing outsourcing, then outsourcing contributes to a more progressive tax structure in the sense of decreasing the marginal labor income tax rate implemented for the low-ability type and increasing the marginal labor income tax rate implemented for the high-ability type. The intuition is that the income tax in this case serves as an indirect instrument to reduce the level of outsourcing (via the policy response just described) and, therefore, avoid part of the wage-inequality that outsourcing would otherwise give rise to. ${ }^{3}$

3 In economies with equilibrium unemployment, outsourcing may also imply lost employment opportunities for the domestic labor force. Aronsson and Koskela (2009b) analyze optimal taxation and provision of a public input good in an economy with equilibrium unemployment (due to a minimum wage policy implemented for the low-ability type). Their results show, among other things, that the appearance of outsourcing provides an incentive for the government to increase the provision of the public input good. See also Keuschnigg and Ribi (2009), who investigate the consequences of outsourcing for unemployment insurance and redistributive linear taxation in an economy with unemployment. Wage and employment responses to labor taxation and/or specific labor tax reforms in economies with outsourcing and involuntary unemployment are analyzed by Koskela and Schöb (2008) and Koskela and Poutvaara (2008a, 2008b, 2009). Ethier (2005) addresses the policy tradeoff between a lower skill premium and employment among the lowskilled in a country undertaking outsourcing. 
Our study contributes to the literature in, at least, three ways. First, by considering a dynamic economy, we are able to analyze how the appearance of outsourcing modifies the structure of optimal capital income taxation; not just the labor income tax. As far as we know, there are no earlier studies dealing with the optimal mix of labor and capital income taxation in this particular context. ${ }^{4}$ Such a study is clearly relevant, as the incentives for capital formation provides an additional channel via which public policy may influence the level of outsourcing. It also relevant as a complement to the study by Aronsson and Koskela (2009a) mentioned above, which only considers optimal labor income taxation. Second, earlier studies dealing with public policy in economies with outsourcing have typically focused attention on the country whose firms outsource production abroad; not on the host-country whose residents receive income from abroad. ${ }^{5}$ The present study, on the other hand, considers a two-country economy, where one of the countries (referred to as the North) moves part of its production to another country (referred to as the South). We will then characterize the optimal tax structure as the outcome of a noncooperative Nash game between the two national governments. Third, outsourcing gives rise to international externalities, which are not fully internalized by the policies implemented by national governments. This suggests that policy cooperation (if properly designed) may lead to higher social welfare. We will, therefore, also analyze some aspects of tax policy cooperation. ${ }^{6}$ To the best of our knowledge, this is a novel aspect in the literature on taxation and outsourcing.

The outline of the study is as follows. Section 2 describes the model, which is an overlapping generations (OLG) economy with two countries, North and South, and two ability-types in each country, where each consumer lives for two periods. In the first period, the consumer works and saves; in the second, he/she is retired. In each country, firms produce a homogeneous good by using labor (of both ability-types) and capital. In

$4 \quad$ Earlier studies on optimal nonlinear taxation in dynamic models address a variety of issues such as, e.g., the conditions under which we ought to use, or not use, capital income taxation as a supplement to the labor income tax in an economy with competitive markets (Ordover and Phelps, 1979; Brett, 1997; Pirttilä and Tuomala, 2001); the consequences of equilibrium unemployment for optimal income taxation (Aronsson et al. 2009); and optimal income taxation in economies where the consumers have positional preferences (Aronsson and Johansson-Stenman, in press).

5 An exception is the study by Egger and Falkinger (2006), which examines the implications of public infrastructure investments in a two-country economy. But in their model they use lump-sum taxes to finance government investments.

6 Aronsson and Sjögren (2004) have considered coordinated policy reforms in terms of the marginal taxation of labor income, the unemployment benefit and the provision of a public good in a rightto-manage wage formation model in the absence of outsourcing. 
addition, the firms in the North may also locate production activities carried out by lowskilled labor to the South (where the before-tax wage rate is lower). To be able to capture the effects of outsourcing in a simple way, we abstract from other sources of interaction between the countries. This simplification enables us to avoid the issue of tax competition for mobile production factors, which has been studied extensively in

other literature. ${ }^{7}$ Section 3 concerns the optimal tax structure implicit in a noncooperative Nash equilibrium. Our results show, among other things, that the appearance of outsourcing provides an incentive for the government in the North to implement a lower marginal labor income tax rate for the low-ability type and a higher marginal labor income tax rate for the high-ability type, i.e. in this sense a more progressive labor income tax structure, as well as implementing higher marginal capital income tax rates for both ability-types than it would otherwise have done. The policy responses to outsourcing by the southern government are, in general, ambiguous, as the desire to relax the self-selection constraint counteracts the incentive to increase the budgetary gain of outsourcing. We also show that the appearance outsourcing extends the production-inefficiency arguments for capital income taxation discussed in earlier literature (Pirttilä and Tuomala 2001, Aronsson et al. 2009), as outsourcing affects the incentives for capital formation and, therefore, the wage distribution in both countries.

Since the tax policy implemented by each national government in the noncooperative Nash equilibrium directly affects the well-being of the residents in the other country as well, the noncooperative equilibrium is not efficient from the perspective of society as a whole. In Section 4, therefore, we address tax policy cooperation. We show how joint agreements among the countries to change the marginal labor and/or capital income tax rates can be designed to increase the welfare. The results are summarized and discussed in Section 5.

\section{The Model}

In this section, we consider an OLG economy comprising two countries, which will be referred to as North $(n)$ and South $(s)$. We assume that North outsources part of its

$7 \quad$ See, e.g. Wilson $(1986,1999)$. 
production to South, which will be addressed more thoroughly below. Below, we describe the consumers and firms as well as the outcome of private optimization.

\subsection{Consumers}

In each country, the consumers live for two periods. Following the approach in earlier comparable literature, we assume that the consumer works during the first period of life and does not work during the second. There are two types of consumers; a low-ability type (denoted by superindex 1) and a high-ability type (denoted by superindex 2 ). The distinction between ability-types refers to productivity, which is interpreted to mean that the high-ability type faces a higher before tax wage rate than the low-ability type. As the number of individuals of each ability-type and generation is not important for our understanding of the optimal policy responses to outsourcing, it will be normalized to one in what follow. This also means that we abstract from population growth.

The utility function facing ability-type $i$ in country $j$ born in the beginning of period $t$ is given by (for $i=1,2$ and $j=n, s$ )

$$
u_{j, t}^{i}=u\left(c_{j, t}^{i}, x_{j, t+1}^{i}, z_{j, t}^{i}\right)
$$

where $c$ denotes consumption when young, $x$ consumption when old and $z$ leisure when young (when old, all time available is used for leisure). Leisure is, in turn, defined as a time endowment, $H$, less the time spent in market work, $l$.

Let $w$ and $\kappa$ denote the before-tax hourly wage rate and saving, respectively, and $r$ denote the before-tax interest rate. The individual budget constraint can then be written as

$$
\begin{aligned}
& w_{j, t}^{i} l_{j, t}^{i}-T_{j, t}\left(w_{j, t}^{i} l_{j, t}^{i}\right)-\kappa_{j, t}^{i}=c_{j, t}^{i} \\
& \kappa_{j, t}^{i}\left(1+r_{j, t+1}\right)-\Phi_{j, t+1}\left(\kappa_{j, t}^{i} r_{j, t+1}\right)=x_{j, t+1}^{i}
\end{aligned}
$$


in which $T_{j, t}\left(w_{j, t}^{i} l_{j, t}^{i}\right)$ and $\Phi_{j, t+1}\left(\kappa_{j, t}^{i} r_{t+1}\right)$ represent the labor income tax paid in period $t$ and capital income tax paid in period $t+1$, respectively. Note that the tax functions may vary over time and across countries. The consumer prices are normalized to one for notational convenience.

The first order conditions for hours of work and savings, respectively, become

$$
\begin{aligned}
& u_{j, t, c}^{i} w_{j, t}^{i}\left(1-T_{j, t}^{\prime}\left(w_{j, t}^{i} l_{j, t}^{i}\right)\right)-u_{j, t, z}^{i}=0 \\
& -u_{j, t, c}^{i}+u_{j, t, x}^{i}\left[1+r_{j, t+1}-\Phi_{j, t+1}^{\prime}\left(\kappa_{j, t}^{i} r_{j, t+1}\right) r_{j, t+1}\right]=0
\end{aligned}
$$

where we have used $u_{j, t, c}^{i}=\partial u_{j, t}^{i} / \partial c_{j, t}^{i}, u_{j, t, z}^{i}=\partial u_{j, t}^{i} / \partial z_{j, t}^{i}$ and $u_{j, t, x}^{i}=\partial u_{j, t}^{i} / \partial x_{j, t+1}^{i}$. In equation (4), $T_{j, t}^{\prime}\left(w_{j, t}^{i} l_{j, t}^{i}\right)$ denotes the marginal labor income tax rate, whereas $\Phi_{j, t+1}^{\prime}\left(\kappa_{j, t}^{i} r_{j, t+1}\right)$ in equation (5) denotes the marginal capital income tax rate.

\subsection{Production}

Turning to the production side of the economy, we assume that each country is characterized by identical competitive firms producing a homogenous good under constant returns to scale using labor of both ability-types and capital. For notational convenience, we normalize the number of firms in each country to one. As we mentioned above, one of the countries, referred to as North $(j=n)$, locates part of its production in the other country, referred to as South $(j=s)$. To be more specific, we assume that the firms in the North partly use unskilled labor from the South in their production and have to pay the Southern low-skilled wage rate for their services.

\section{Production in the North}

By analogy to Koskela and Stenbacka (2007), the production function is written as $F_{n}\left(l_{n, t}^{1}+\delta l_{n s, t}^{1}, l_{n, t}^{2}, K_{n, t}\right)$, where $K$ is the capital stock. We assume that the production function is increasing in each of its three arguments, and that the production factors are 
technical complements in the sense that $F_{n, l^{1} l^{2}}>0, F_{n, l^{1} K}>0$ and $F_{n, l^{2} K}>0 .{ }^{8}$ The variable $l_{n s, t}^{1}$ is the low-skilled labor (measured in work hours) by residents in the South that are used by northern firms. The parameter $\delta$ captures the idea that foreign labor may not be a perfect substitute for domestic labor; therefore, one would normally expect that $0<\delta<1$. In our framework, outsourcing is substitutable for domestic unskilled labor and complementary with domestic skilled labor, implying that outsourcing leads to more wage inequality in the North. As mentioned above, this property is conformity with empirical evidence (see footnote 2). Ethier (2005) uses a similar production function (yet based on a specific functional form assumption) to study the effects of globalization on the skill premium. There is also a capacity aspect of outsourcing, as the firm needs to build costly capacity abroad. We assume that while some activities are easy to outsource, other activities are more costly. Therefore, the marginal cost of outsourcing increases in the scope of activities to outsource, so that there is a capacity cost of outsourcing, $\psi\left(l_{n s, t}^{1}\right)$, which is increasing and convex, i.e. $\psi^{\prime}\left(l_{n s, t}^{1}\right)>0, \psi^{\prime \prime}\left(l_{n s, t}^{1}\right) \geq 0$. This formulation captures the idea that outsourcing may necessitate costly investments into the establishment of network of suppliers in relevant host-countries.

The objective function facing the firm at any time, $t$, can be written as

$$
\pi_{n, t}=F_{n}\left(l_{n, t}^{1}+\delta l_{n s, t}^{1}, l_{n, t}^{2}, K_{n, t}\right)-w_{n, t}^{1} l_{n, t}^{1}-w_{n, t}^{2} l_{t}^{2}-\psi\left(l_{n s, t}^{1}\right)-w_{s, t}^{1} l_{n s, t}^{1}-r_{n, t} K_{n, t}
$$

where (as before) $w_{n, t}^{1}$ and $w_{n, t}^{2}$ denote the before-tax wage rates paid to low-skilled and high-skilled labor, respectively, and $r_{n, t}$ denotes the interest rate, while $w_{s, t}^{1}$ is the before tax wage rate paid to low-skilled labor the South in period $t$. The first order conditions become

$$
F_{n, l^{1}}\left(l_{n, t}^{1}+\delta l_{n s, t}^{1}, l_{n, t}^{2}, K_{n, t}\right)-w_{n, t}^{1}=0
$$

Instead of splitting the production function into a domestic and foreign part, we simplify by considering a single production function for the representative firm. Given the assumptions made above, this is not important for the results. 


$$
\begin{aligned}
& F_{n, l^{2}}\left(l_{n, t}^{1}+\delta l_{n s, t}^{1}, l_{n, t}^{2}, K_{n, t}\right)-w_{n, t}^{2}=0 \\
& F_{n, K}\left(l_{n, t}^{1}+\delta l_{n s, t}^{1}, l_{n, t}^{2}, K_{n, t}\right)-r_{n, t}=0 \\
& \delta F_{n, l^{1}}\left(l_{n, t}^{1}+\delta l_{n s, t}^{1}, l_{n, t}^{2}, K_{n, t}\right)-\psi_{l^{1}}\left(l_{n s, t}^{1}\right)-w_{s, t}^{1}=0 .
\end{aligned}
$$

By using equation (9), we can write $l_{n s, t}^{1}$ as a function $l_{n, t}^{1}, l_{n, t}^{2}, K_{n, t}$ (variables that the government in the North controls via tax policy; see below) and $w_{s, t}^{1}$, i.e.,

$$
l_{n s, t}^{1}=l_{n s}^{1}\left(l_{n, t}^{-}, \stackrel{+}{l_{n, t}^{2}}, K_{n, t}^{+}, w_{s, t}^{-}\right)
$$

where sign-indicator above each argument shows the qualitative comparative statics effect.

\section{Production in the South}

Let $l_{s, t}^{1}=l_{d s, t}^{1}+l_{n s, t}^{1}$ be the total labor supply in the South, where $l_{d s, t}^{1}$ is the low-skilled labor supplied to domestic production in the southern economy. The production function is written as $F_{s}\left(l_{s, t}^{1}-l_{n s, t}^{1}, l_{s, t}^{2}, K_{s, t}\right)$ and is assumed to have the same qualitative properties as the production function for the North described above, i.e. $F_{s . l^{1} l^{2}}>0$, $F_{s . l^{1} K}>0$ and $F_{s . l^{2} K}>0$. The objective function of the representative firm is given by

$$
\pi_{s, t}=F_{s}\left(l_{s, t}^{1}-l_{n s, t}^{1} l_{s, t}^{2}, K_{s, t}\right)-w_{s, t}^{1}\left(l_{n, t}^{1}-l_{s n, t}^{1}\right)-w_{s, t}^{2} l_{s, t}^{2}-r_{s, t} K_{s, t}
$$

The first order conditions become

$$
\begin{aligned}
& F_{s, l^{1}}\left(l_{s, t}^{1}-l_{n s, t}^{1}, l_{s, t}^{2}, K_{s, t}\right)-w_{s, t}^{1}=0 \\
& F_{s, l^{2}}\left(l_{s, t}^{1}-l_{n s, t}^{1}, l_{s, t}^{2}, K_{s, t}\right)-w_{s, t}^{2}=0 \\
& F_{s, K}\left(l_{s, t}^{1}-l_{n s, t}^{1}, l_{s, t}^{2}, K_{s, t}\right)-r_{s, t}=0 .
\end{aligned}
$$


For further use, note that equations (10) and (11) implicitly define the low-skilled wage rate in the South as a function of the hours of work and capital stock in both countries, i.e.

$$
w_{s, t}^{1}=w_{s}^{1}\left(l_{s, t}^{-}, \stackrel{+}{l_{s, t}^{2}}, \stackrel{+}{+}, K_{s, t}^{-}, \stackrel{+}{l_{n, t}^{1}}, l_{n, t}^{2}, K_{n, t}^{+}\right) .
$$

The intuition behind equation (14) is straight forward. For the variables accruing to the South, the influence of $l_{s, t}^{1}$ reflects a labor supply effect on the wage rate (due to concavity of the production function), whereas the qualitative effects of $l_{s, t}^{2}$ and $K_{s, t}$ are due to complementary between, on the one hand, unskilled labor and, on the other, skilled labor and capital. The effects of the northern variables, $l_{n, t}^{1}, l_{n, t}^{2}$ and $K_{n, t}$, follow from the properties of the production function in the North in combination with equation (10) above.

\section{Optimal Taxation in a Noncooperative Equilibrium}

In this section, we begin by a presentation of the decision-problem facing each national government. We will then turn to the outcome in terms of optimal taxation of labor income and capital income at the national level, in case the two national governments act as Nash competitors to one another.

Each national government is assumed to face the following general social welfare function ${ }^{9}$;

$$
W_{j}=W_{j}\left(u_{j, 0}^{1}, u_{j, 0}^{2}, u_{j, 1}^{1}, u_{j, 1}^{2}, \ldots .\right)
$$

for $j=n, s$, which allows for a unique welfare weight attached to the utility function of each ability-type and generation.

Another approach would be to assume that the government aims at maximizing the utility of one particular ability-type and generation subject to minimum utility restrictions for all other abilitytypes and generations. If we were to use this alternative approach (instead of using the social welfare function), all qualitative results derived below would remain unchanged. 
The informational assumptions are conventional: the government knows the income of each individual as well as the number of individuals of each ability-type, whereas ability is private information. This means that the government is not able to observe whether any given worker is a low-ability or high-ability type. By concentrating on the "normal" case, where redistribution means income transfers from the high-ability to the low-ability type, one would like to prevent the high-ability type from mimicking the low-ability type in order to gain from redistribution. The self-selection constraint that may bind then becomes

$$
u_{j, t}^{2}=u\left(c_{j, t}^{2}, x_{j, t+1}^{2}, z_{j, t}^{2}\right) \geq u\left(c_{j, t}^{1}, x_{j, t+1}^{1}, H-\phi_{j, t} l_{j, t}^{1}\right)=\hat{u}_{j, t}^{2}
$$

where $\hat{u}_{j, t}^{2}$ denotes the utility of the mimicker and $\phi_{j, t}=w_{j, t}^{1} / w_{j, t}^{2}<1$ the wage ratio, i.e. the relative wage rate, in period $t$. Note that the mimicker faces the same income and consumption point in both periods and, therefore, pays as much tax as the low-ability type. However, as the mimicker is more productive than the low-ability type, he/she spends more time on leisure. We can interpret $\phi_{j, t} l_{j, t}^{1}$ as the labor that the mimicker needs to supply in order to reach the same income as the low-ability type. By using the first order conditions for the firm, the wage ratio can be written as

$$
\phi_{j, t}=\phi_{j}\left(l_{j, t}^{1}, l_{j, t}^{2}, K_{j, t}, l_{n s, t}^{1}\right) .
$$

For further use, note that $\partial \phi_{n, t} / \partial l_{n s, t}^{1}<0$ and $\partial \phi_{s, t}^{1} / \partial l_{n s, t}^{1}>0$. In other words, increased outsourcing leads to more wage inequality in the North and less wage inequality in the South. ${ }^{10}$

10 These properties are easily seen if we write the wage ratios as follows;

$$
\begin{gathered}
\phi_{n, t}=\frac{w_{n, t}^{1}}{w_{n, t}^{2}}=\frac{F_{n, l^{1}}\left(l_{n, t}^{1}+\delta l_{n s, t}^{1}, l_{n, t}^{2}, K_{n, t}\right)}{F_{n, l^{2}}\left(l_{n, t}^{1}+\delta l_{n s, t}^{1}, l_{n, t}^{2}, K_{n, t}\right)} \\
\phi_{s, t}=\frac{w_{s, t}^{1}}{w_{s, t}^{2}}=\frac{F_{s, l^{1}}\left(l_{s, t}^{1}-l_{n s, t}^{1}, l_{s, t}^{2}, K_{s, t}\right)}{F_{s, l^{2}}\left(l_{s, t}^{1}-l_{n s, t}^{1}, l_{s, t}^{2}, K_{s, t}\right)}
\end{gathered}
$$


As we abstract from publicly provided goods, the resource constraint facing each national government can be written as

$$
\begin{aligned}
& K_{n, t+1}-K_{n, t}=F_{n}\left(l_{n, t}^{1}+\delta l_{n s, t}^{1}, l_{n, t}^{2}, K_{n, t}\right)-c_{n, t}^{1}-c_{n, t}^{2}-x_{n, t}^{1}-x_{n, t}^{2}-w_{s, t}^{1} l_{n s, t}^{1} \\
& K_{s, t+1}-K_{s, t}=F_{s}\left(l_{s, t}^{1}-l_{n s, t}^{1}, l_{s, t}^{2}, K_{s, t}\right)-c_{s, t}^{1}-c_{s, t}^{2}-x_{s, t}^{1}-x_{s, t}^{2}+w_{s, t}^{1} l_{n s, t}^{1}
\end{aligned}
$$

which imply that output is used for private consumption and net investments. The final term on the right hand side of each resource constraint arises because outsourcing gives rise to an income effect, which differs between the countries. This is so because part of the income generated by the North accrues to residents in the South.

As the nonlinear taxes on labor income and capital income analyzed here imply that each national government can control the domestic consumption and work hours by each ability-type as well as the domestic capital stock, we follow the bulk of earlier literature on the self-selection approach to optimal taxation by considering a direct decision-problem. The decision-problem facing each national government will be written such that the government chooses hours of work, consumption and capital stock in order to maximize the social welfare function presented in equation (15) subject to the self-selection constraint and the resource constraint given by equation (16) and (18), respectively. We can then derive the optimal marginal (labor and capital) income tax rates needed to implement the second best resource allocation by combining the first order conditions for the government with those of the private sector.

\subsection{Optimal Taxation in the North}

The optimal tax problem in the North will be written such that the government chooses $l_{n, t}^{1}, c_{n, t}^{1}, x_{n, t}^{1}, l_{n, t}^{2}, c_{n, t}^{2}, x_{n, t}^{2}$ and $K_{n, t}$ for all $t$ to maximize the Lagrangean

and then differentiate with respect to $l_{n s, t}^{1}$. 


$$
\begin{aligned}
L_{n} & =W_{n}+\sum_{t} \lambda_{n, t}\left[u_{n, t}^{2}-\hat{u}_{n, t}^{2}\right]+\sum_{t} \gamma_{n, t}\left[F_{n, t}-c_{n, t}^{1}-c_{n, t}^{2}-x_{n, t}^{1}-x_{n, t}^{2}-\psi\left(l_{n s, t}^{1}\right)\right. \\
& \left.-w_{s, t}^{1} l_{n s, t}^{1}+K_{n, t}-K_{n, t+1}\right]
\end{aligned}
$$

in which $F_{n, t}$ denotes the production function as specified in equation (18a) above. The government in the North recognizes that that $l_{n s, t}^{1}, w_{s, t}^{1}$ and $\phi_{n, t}$ are determined by equation (10), (14) and (17), respectively, while treating the decision-variables of the southern government (i.e. $l_{s, t}^{1}, c_{s, t}^{1}, x_{s, t}^{1}, l_{s, t}^{2}, c_{s, t}^{2}, x_{s, t}^{2}$ and $K_{s, t}$ for all $t$ ) as exogenous. The first order conditions are presented in the Appendix.

To simplify the presentation of the results, we begin by deriving the welfare effect for the North of a small increase in outsourcing, i.e. a small increase in $l_{n s, t}^{1}$. By using the first order conditions for the firm, we can derive

$$
\Lambda_{n, t}=\frac{\partial L_{n} / \partial l_{n s, t}^{1}}{\gamma_{n, t}}=\frac{\lambda_{n, t}}{\gamma_{n, t}} \hat{u}_{n, t, z}^{2} l_{n, t}^{1} \frac{\partial \phi_{n, t}}{\partial l_{n s, t}^{1}}<0
$$

Equation (19) means that increased outsourcing leads to more wage-inequality and, therefore, reduces welfare in the North. Now, recall from equations (10) and (14) that the government in the North may influence $l_{n s, t}^{1}$ by changing $l_{n, t}^{1}, l_{n, t}^{2}$ and $K_{n, t}$. We can derive the following total derivatives;

$$
\begin{gathered}
\frac{d l_{n s, t}^{1}}{d l_{n, t}^{1}}=\frac{\partial l_{n s, t}^{1}}{\partial l_{n, t}^{1}}+\frac{\partial l_{n s, t}^{1}}{\partial w_{s, t}^{1}} \frac{\partial w_{s, t}^{1}}{\partial l_{n, t}^{1}} \\
\frac{d l_{n s, t}^{1}}{d l_{n, t}^{2}}=\frac{\partial l_{n s, t}^{1}}{\partial l_{n, t}^{2}}+\frac{\partial l_{n s, t}^{1}}{\partial w_{s, t}^{1}} \frac{\partial w_{s, t}^{1}}{\partial l_{n, t}^{2}} \\
+ \\
\frac{d l_{n s, t}^{1}}{d K_{n, t}}=\frac{\partial l_{n s, t}^{1}}{\partial K_{n, t}}+\frac{\partial l_{n s, t}^{1}}{\partial w_{s, t}^{1}} \frac{\partial w_{s, t}^{1}}{\partial K_{n, t}} .
\end{gathered}
$$

Therefore, an increase in $l_{n, t}^{1}, l_{n, t}^{2}$ and $K_{n, t}$, respectively, affects $l_{n s, t}^{1}$ via two channels; first, a direct effect (measured by equation (10) with $w_{s, t}^{1}$ held constant) and, second, an indirect effect via $w_{s, t}^{1}$ (defined by equation (11)). As the sign below each component 
indicates, none of these total derivatives can be signed in the general case. To be able to relate our results to those presented by Aronsson and Koskela (2009a), we add the assumption that the direct effect of $l_{n, t}^{1}, l_{n, t}^{2}$ and $K_{n, t}$, respectively, dominates the corresponding indirect effect via the foreign wage rate for southern low-skilled labor. This assumption is based on the idea that the amount of southern labor used by northern firms is small relative to the aggregate hours of work supplied by the low-skilled in the South, which means that the behavior of northern firms have a relatively modest effect on the wage rate facing the low-skilled in the South. Formally, our assumption is summarized as follows;

A1. $\operatorname{sign} \frac{d l_{n s, t}^{1}}{d l_{n, t}^{1}}=\operatorname{sign} \frac{\partial l_{n s, t}^{1}}{\partial l_{n, t}^{1}}, \operatorname{sign} \frac{d l_{n s, t}^{1}}{d l_{n, t}^{2}}=\operatorname{sign} \frac{\partial l_{n s, t}^{1}}{\partial l_{n, t}^{2}}$ and $\operatorname{sign} \frac{d l_{n s, t}^{1}}{d K_{n, t}}=\operatorname{sign} \frac{\partial l_{n s, t}^{1}}{\partial K_{n, t}}$.

The marginal labor income tax rate of the low-ability type can be derived by combining equations (A1), (A2) and (4), while the marginal labor income tax rate of the high-ability type is derived by combining equations (A4), (A5) and (4). Let

$$
M R S_{n, z, c}^{i, t}=\frac{\partial u_{n, t}^{i} / \partial z_{n, t}^{i}}{\partial u_{n, t}^{i} / \partial c_{n, t}^{i}} \text { and } M \hat{R} S_{n, z, c}^{2, t}=\frac{\partial \hat{u}_{n, t}^{2} / \partial \hat{z}_{n, t}^{2}}{\partial \hat{u}_{n, t}^{2} / \partial c_{n, t}^{1}}
$$

denote the marginal rate of substituting between leisure and private consumption for the young ability-type $i$ and the young mimicker, respectively. We show in the Appendix that the marginal labor income tax rates can be written as

$$
\begin{aligned}
T_{n, t}^{\prime}\left(w_{n, l}^{1} l_{n, t}^{1}\right) & =\frac{\lambda_{n, t}^{*}}{w_{n, t}^{1}}\left[M R S_{n, z, c}^{1, t}-\phi_{n, t} M \hat{R} S_{n, z, c}^{2, t}\right]-\frac{\lambda_{n, t}}{\gamma_{n, t} w_{n, t}^{1}} \hat{u}_{n, t, z}^{2} l_{n, t}^{1} \frac{\partial \phi_{n, t}}{\partial l_{n, t}^{1}} \\
& \underbrace{-\frac{\Lambda_{n, t}}{w_{n, t}^{1}} \frac{d l_{n s, t}^{1}}{d l_{n, t}^{1}}}_{-} \underbrace{\frac{\partial w_{s, t}^{1}}{\partial l_{n, t}^{1}} \frac{l_{n s, t}^{1}}{w_{n, t}^{1}}}_{-} \\
T_{n, t}^{\prime}\left(w_{n, l}^{2} l_{n, t}^{2}\right) & =-\frac{\lambda_{n, t}}{\gamma_{n, t} w_{n, t}^{2}} \hat{u}_{n, t, z}^{2} l_{n, t}^{1} \frac{\partial \phi_{n, t}}{\partial l_{n, t}^{2}} \underbrace{\frac{\Lambda_{n, t}}{w_{n, t}^{2}} \frac{d l_{n s, t}^{1}}{d l_{n, t}^{2}}}_{+} \underbrace{\frac{\partial w_{s, t}^{1}}{\partial l_{n, t}^{2}} \frac{l_{n s, t}^{1}}{w_{n, t}^{2}}}_{+} .
\end{aligned}
$$

In equation (20), the first term on the right hand side is due to the self-selection constraint and contributes to increase the marginal labor income tax rate of the lowability type. The intuition is that a higher marginal labor income tax rate makes 
mimicking less attractive, ceteris paribus, and, therefore, creates room for additional redistribution. Also the second term on the right hand side of equation (20) and the analogous first term on the right hand side of equation (21) reflect the self-selection although for a different reason: changes in $l_{n, t}^{1}$ and $l_{n, t}^{2}$ affect the wage ratio and, therefore, the labor that the mimicker needs to supply in order to reach the same income as the low-ability type. Normally, we would expect this component to increase the marginal labor income tax rate of the low-ability type and decrease the marginal income tax rate of the high-ability type. These effects - which would also appear without outsourcing - are well understood from earlier research (Stiglitz, 1982).

The final two terms on the right hand side of equation (20) and (21), respectively, are due to the appearance of outsourcing; the first arises because a change in the use of outsourced labor affects the self-selection constraint, and the second is a budget effect due to that the domestic factor income no longer matches domestic output. We will refer to the joint effect of these two terms as the direct effect of outsourcing. With assumption A1 at our disposal, both these components contribute negatively to the marginal labor income tax rate of the low-ability type and positively to the marginal labor income tax rate of the high-ability type. The intuition is that an increase (a decrease) in the hours of work supplied by the low-ability (high-ability) type leads to less outsourcing, which contributes to relax the self-selection constraint and reduce the payment to foreign residents. This is analogous to a result derived by Aronsson and Koskela (2009a), yet with the modification that the budget effect was absent in their study. The implications of outsourcing for the marginal labor income tax structure are summarized as follows;

Proposition 1. In the North, and under assumption A1, the direct effect of outsourcing is to decrease the marginal labor income tax rate of the lowability type and increase the marginal labor income tax rate of the highability type.

Proposition 1 is interpretable to mean that the outsourcing contributes to a more progressive labor income tax structure in the country that outsources production abroad. This policy response causes the level of outsourcing to decrease which, in turn, leads to less wage-inequality and reduces the payments to foreign residents. 
Let us then turn to the marginal capital income tax rates. Define

$$
M R S_{n, c, x}^{i, t}=\frac{\partial u_{n, t}^{i} / \partial c_{n, t}^{i}}{\partial u_{n, t}^{i} / \partial x_{n, t+1}^{i}} \text { and } M \hat{R} S_{n, c, x}^{2, t}=\frac{\partial \hat{u}_{n, t}^{2} / \partial c_{n, t}^{1}}{\partial \hat{u}_{n, t}^{2} / \partial x_{n, t+1}^{1}}
$$

to be the marginal rate of substitution between the present and future consumption for ability type $i$ and the mimicker, respectively. For the low-ability type, the marginal capital income tax rate can be derived by combining equations (A2), (A3), (A7) and (5), and for the high-ability type by combining equations (A5), (A6), (A7) and (5). We show in the Appendix that the marginal capital income tax rates can be written as

$$
\begin{gathered}
\Phi_{n, t+1}^{\prime}\left(\kappa_{n, t}^{1} r_{n, t+1}\right)=\frac{\lambda_{n, t} \hat{u}_{n, t, x}^{2}}{\gamma_{n, t+1} r_{n, t+1}}\left[M R S_{n, c, x}^{1, t}-M \hat{R} S_{n, c, x}^{2, t}\right]-\frac{\lambda_{n t+1} \hat{u}_{n, t+1, z}^{2} l_{n, t+1}^{1}}{\gamma_{n, t+1} r_{n, t+1}} \frac{\partial \phi_{n, t+1}}{\partial K_{n, t+1}} \\
-\underbrace{\frac{\Lambda_{n, t+1}}{r_{n, t+1}} \frac{d l_{n s, t}^{1}}{d K_{n, t+1}}}_{+}+\underbrace{\frac{1}{r_{n, t+1}} \frac{\partial w_{s, t}^{1}}{\partial K_{n, t+1}} l_{n s, t}^{1}}_{+} \\
\Phi_{n, t+1}^{\prime}\left(\kappa_{n, t}^{2} r_{n, t+1}\right)=-\frac{\lambda_{n, t+1} \hat{u}_{n, t+1, z}^{2} l_{n, t+1}^{1}}{\gamma_{n, t+1} r_{n, t+1}} \frac{\partial \phi_{n, t+1}}{\partial K_{n, t+1}} \underbrace{-\frac{\Lambda_{n, t+1}}{r_{n, t+1}} \frac{d l_{n s, t}^{1}}{d K_{n, t+1}}}_{+} \underbrace{\frac{1}{r_{n, t+1}} \frac{\partial w_{s, t}^{1}}{\partial K_{n, t+1}} l_{n s, t}^{1}}_{+} .
\end{gathered}
$$

The first row on the right hand side of equation (22), and the first term on the right hand side of equation (23), reflect motives for capital income taxation that are well understood from earlier literature (e.g., Brett 1997; Pirttilä and Tuomala 2001). We summarize these incentive effects as follows. If $M R S_{n, c, x}^{1, t}>(<) M \hat{R} S_{n, c, x}^{2, t}$, meaning that the low-ability type attaches a higher (lower) relative value to the current consumption than the mimicker, there will be an incentive for the government to encourage (discourage) early consumption for the low-ability type via a higher (lower) marginal capital income tax rate. As such, this incentive effect serves to relax the self-selection constraint, as it makes mimicking less attractive. The second term on the right hand side of equation (22) and the analogous first term on the right hand side of equation (23) appear because a change in the capital stock directly affects the wage ratio and, therefore, also the number of work hours that the mimicker needs to supply in order to reach the same income as the low-ability type. If $\partial \phi_{n, t+1} / \partial K_{n, t+1}>0(<0)$, meaning that 
an increase (a decrease) in the capital stock contributes to relax the self-selection constraint, there is an incentive for the government to encourage (discourage) savings by implementing lower (higher) marginal capital income tax rates for both ability-types than it would otherwise have done.

In a way similar to the marginal labor income tax rates discussed above, the final two terms in each tax formula are due to the appearance of outsourcing, and their joint influence will also in this case be referred as the direct effect of outsourcing. As before, the first component reflects that a change in the use of outsourced labor affects the selfselection constraint, and the second is a budget effect due to that part of the output generated by domestic firms are used to pay for foreign labor services. Given assumption A1, both these components contribute to increase the marginal capital income tax rates. The intuition is that a decrease in the capital stock leads to less outsourcing which, in turn, relaxes the self-selection constraint and reduces the payments to foreign residents. We have derived the following result;

Proposition 2. In the North, and under assumption Al, the direct effect of outsourcing is to increase the marginal capital income tax rates for both ability-types.

In the North, therefore, Propositions 1 and 2 together imply a distinct modification of tax policy by comparison with the standard optimal income tax model: to discourage outsourcing, there is an incentive for the government to implement a more progressive labor income tax structure and higher marginal capital income tax rates than it would otherwise have done.

Note also that the direct effect of outsourcing on the marginal capital income tax rate relates to intertermporal production-inefficiency in an interesting way, as it contributes to a discrepancy between the ratio of shadow prices of capital, $\gamma_{n, t} / \gamma_{n, t+1}$, and the interest factor, $1+r_{n, t+1}$. This is seen from the first order condition for $K_{n, t+1}$, i.e. equation (A7) in the Appendix, which can be written as 


$$
\frac{\gamma_{n, t}}{\gamma_{n, t+1}}-\left(1+r_{n, t+1}\right)=\frac{\lambda_{n, t+1}}{\gamma_{n, t+1}} \hat{u}_{n, t+1, z}^{2} l_{n, t+1}^{1} \frac{\partial \phi_{n, t+1}}{\partial K_{n, t+1}}-\frac{\partial w_{s, t+1}^{1}}{\partial K_{n, t+1}} l_{n s, t+1}^{1}+\Lambda_{n, t+1} \frac{d l_{n s, t+1}^{1}}{d K_{n, t+1}} \neq 0
$$

Equation (24) extends a corresponding result derived by Pirttilä and Tuomala (2001), where the discrepancy between the shadow price ratio and the interest factor was due solely to the first term on the right hand side (as the capital stock has a direct effect on the domestic wage ratio). Here, two additional effects appear as a consequence of outsourcing, which are summarized by the second and third terms on the right hand side. The intuition is, of course, that the capital stock in the northern economy in period $t+1$ is directly correlated with the hours of work by southern low-skilled labor employed by northern firms, $l_{n s, t+1}^{1}$, and the southern low-skilled wage rate, $w_{s, t+1}^{1}$, in period $t+1$. Both these effects contribute to underprovision of capital relative to the first best policy rule.

\subsection{Optimal Taxation in the South}

The optimal tax problem in the southern economy will be written such that the government chooses $l_{s, t}^{1}, c_{s, t}^{1}, x_{s, t}^{1}, l_{s, t}^{2}, c_{s, t}^{2}, x_{s, t}^{2}$ and $K_{s, t}$ for all $t$ in order to maximize the Lagrangean

$$
L_{s}=W_{s}+\sum_{t} \lambda_{s, t}\left[u_{s, t}^{2}-\hat{u}_{s, t}^{2}\right]+\sum_{t} \gamma_{s, t}\left[F_{s, t}-c_{s, t}^{1}-c_{s, t}^{2}-x_{s, t}^{1}-x_{s, t}^{2}+w_{s, t}^{1} l_{n s, t}^{1}+K_{s, t}-K_{s, t+1}\right]
$$

subject to equations (10), (14) and (17). The government in the South treats the decision-variables of the northern government as exogenous. The first order conditions are presented in the Appendix.

Income taxation in the South is governed by the same general incentives as in the North with two important exceptions. First, increased outsourcing leads to less wage inequality and, therefore, higher welfare for the South. This is seen by differentiating the Lagrangean with respect to $l_{n s, t}^{1}$ and using the first order conditions for the firm 


$$
\Lambda_{s, t}=\frac{\partial L_{s} / \partial l_{n s, t}^{1}}{\gamma_{s, t}}=\frac{\lambda_{s, t}}{\gamma_{s, t}} \hat{u}_{s, t, z}^{2} l_{s, t}^{1} \frac{\partial \phi_{s, t}}{\partial l_{n s, t}^{1}}>0 .
$$

Second, increased outsourcing leads to more factor income from abroad. In other words, and contrary to the government in the North, the southern government has an incentive to stimulate outsourcing.

To shorten the notations, and since the components of the tax formulas that are not due to the appearance of outsourcing take the same general form as for the northern economy, we use

$$
\begin{aligned}
\tau_{s, t}^{1} & =\frac{\lambda_{s, t}^{*}}{w_{s, t}^{1}}\left[M R S_{s, z, c}^{1, t}-\phi_{s, t} M \hat{R} S_{s, z, c}^{2, t}\right]-\frac{\lambda_{s, t}}{\gamma_{s, t} w_{s, t}^{1}} \hat{u}_{s, t, z}^{2} l_{s, t}^{1} \frac{\partial \phi_{s, t}}{\partial l_{s, t}^{1}} \\
\tau_{s, t}^{2} & =-\frac{\lambda_{s, t}}{\gamma_{s, t} w_{s, t}^{2}} \hat{u}_{s, t, z}^{2} l_{s, t}^{1} \frac{\partial \phi_{s, t}}{\partial l_{s, t}^{2}}
\end{aligned}
$$

to denote the policy rules for marginal labor income taxation that would apply in the absence of outsourcing. The policy incentives embedded in these formulas are analogous to, and have the same interpretations as, the corresponding effects derived for the North above and will, therefore, not be further discussed here. The marginal labor income tax rates can then be characterized as follows;

$$
\begin{gathered}
T_{s, t}^{\prime}\left(w_{s, t}^{1} l_{s, t}^{1}\right)=\tau_{s, t}^{1} \underbrace{-\frac{\Lambda_{s, t}}{w_{s, t}^{1}} \frac{\partial l_{n s, t}^{1}}{\partial w_{s, t}^{1}} \frac{\partial w_{s, t}^{1}}{\partial l_{s, t}^{1}}}_{-}-\underbrace{\frac{\partial w_{s, t}^{1}}{\partial l_{s, t}^{1}} \frac{l_{n s, t}^{1}}{w_{s, t}^{1}}}_{+} \\
T_{s, t}^{\prime}\left(w_{s, t}^{2} l_{s, t}^{2}\right)=\tau_{s, t}^{2} \underbrace{-\frac{\Lambda_{s, t}}{w_{s, t}^{2}} \frac{\partial l_{n s, t}^{1}}{\partial w_{s, t}^{1}} \frac{\partial w_{s, t}^{1}}{\partial l_{s, t}^{2}}}_{+} \underbrace{\frac{\partial w_{s, t}^{1}}{\partial l_{s, t}^{2}} \frac{l_{n s, t}^{1}}{w_{s, t}^{2}}}_{-} .
\end{gathered}
$$

The final two terms in each tax formula, the joint influence of which is again interpretable as a direct effect of outsourcing, reflect incentives that are in a sense opposite to those facing the northern government, as the South (contrary to the North) has an incentive to encourage outsourcing. Despite this, and somewhat surprisingly, outsourcing affects the marginal labor income tax rates in the southern economy in a way that partly resembles the results derived for the North. This is seen from the second term on the right hand side of equation (25) and (26), respectively, which provides an incentive for the southern government to decrease the marginal labor income tax rate for 
the low-ability-type and increase the marginal labor income tax rate for the high-ability type, although it does so for a different reason than the one behind the analogous policy response in the North. The intuition is, instead, that the southern government can only influence the outsourcing indirectly via the wage rate for the low-ability type. An increase in the hours of work supplied by the low-ability type leads to a lower before tax wage rate for the low-ability type which, in turn, leads to increased outsourcing, i.e. $l_{n s, t}^{1}$ increases. A decrease in the hours of work supplied by the high-ability type also leads to a lower before tax wage rate for the low-ability type (as the two types of labor are complements in terms of the production function) and, therefore, to increased outsourcing. As indicated above, the reason as to why increased outsourcing is desirable in the South is that it relaxes the self-selection constraint.

However, the budget effect (the third term on the right hand side) works in the opposite direction here, as a decrease in the before tax wage rate of the low-ability type reduces the factor income from abroad. Therefore, the budget effect counteracts the incentive to relax the self-selection constraint and implies, instead, an incentive for the government in the South to increase the marginal labor income tax rate of the lowability type and decrease the marginal labor income tax rate of the high-ability type.

We have derived the following result;

Proposition 3. (i) Increased outsourcing leads to less wage inequality for the southern economy and contributes, therefore, to relax the self-selection constraint. This provides an incentive for the government in the South to implement a lower marginal labor income tax rate for the low-ability type and a higher marginal labor income tax rate for the high-ability type than it would otherwise have done. (ii) Reduced hours of work by the lowability type and increased hours of work by the high-ability type contribute to increase the budgetary gain of outsourcing for the southern economy, which provides an incentive for the government in the South to implement a higher marginal labor income tax rate for the low-ability type and a lower marginal labor income tax rate for the high-ability type than it would otherwise have done. 
Therefore, and contrary to the results derived for the northern economy, the two terms comprising the direct effect of outsourcing in each tax formula work in opposite directions here. The relative size of these components determines whether outsourcing motivates higher or lower marginal labor income tax rates than in the standard optimal income tax model without outsourcing.

Turning to capital income taxation, we use $\mu_{s, t+1}^{1}$ and $\mu_{s, t+1}^{2}$, respectively, as a short notation for the marginal capital income tax formula that would apply in the absence of outsourcing, i.e. the marginal capital income tax rate in the standard twotype model. We have

$$
\begin{aligned}
\mu_{s, t+1}^{1} & =\frac{\lambda_{s, t} \hat{u}_{s, t, x}^{2}}{\gamma_{s, t+1} r_{s, t+1}}\left[M R S_{s, c, x}^{1, t}-M \hat{R} S_{s, c, x}^{2, t}\right]-\frac{\lambda_{s, t+1} \hat{u}_{s, t+1, z}^{2} l_{s, t+1}^{1}}{\gamma_{s, t+1} r_{s, t+1}} \frac{\partial \phi_{s, t+1}}{\partial K_{s, t+1}} \\
\mu_{s, t+1}^{2} & =-\frac{\lambda_{s, t+1} \hat{u}_{s, t+1, z}^{2} l_{s, t+1}^{1}}{\gamma_{s, t+1} r_{s, t+1}} \frac{\partial \phi_{s, t+1}}{\partial K_{s, t+1}}
\end{aligned}
$$

which are analogous to their counterparts for the northern economy analyzed above and will not be further discussed here. We can then write the marginal capital income tax rates in the South as follows;

$$
\Phi_{s, t+1}^{\prime}\left(\kappa_{s, t}^{i} r_{n, t+1}\right)=\mu_{s, t+1}^{i} \underbrace{-\frac{\Lambda_{s, t+1}}{r_{s, t+1}} \frac{\partial l_{n s, t+1}^{1}}{\partial w_{s, t+1}^{1}} \frac{\partial w_{s, t+1}^{1}}{\partial K_{s, t+1}}}_{+} \underbrace{\frac{1}{r_{s, t+1}} \frac{\partial w_{s, t+1}^{1}}{\partial K_{n, t+1}} l_{n s, t+1}^{1}}_{-} \text {for } i=1,2
$$

By analogy to the effects of outsourcing on the marginal labor income tax rates, outsourcing gives rise to two counteracting effects on the marginal capital income tax rate. First, a decrease in the capital stock leads to a lower pre-tax wage rate for the lowability type which, in turn, leads to increased outsourcing. This effect is summarized by the second term on the right hand side of equation (27) and provides an incentive for the government to increase the marginal capital income tax rates for both ability-types. The intuition is that increased outsourcing leads to a relaxation of the self-selection constraint and, therefore, increased welfare in the southern economy. Second, the lower 
before tax wage rate following a decrease in the capital stock reduces the factor income from abroad, which implies a welfare loss for the southern economy. To avoid this welfare loss, there is an incentive for the government to implement lower marginal capital income tax rates, which explains the final term on the right hand side of the tax formula. Note also that, if we were to derive a counterpart to equation (24) for the southern economy, we may also in this case interpret the direct effect of outsourcing in each capital tax formula as a consequence of intertemporal production-inefficiency at the second best optimum.

We summarize the effects of outsourcing on the marginal capital income tax rates by the following proposition;

Proposition 4. (i) A decrease in the capital stock leads to a lower pre-tax wage rate for the low-ability type, ceteris paribus, which contributes to increased outsourcing and, therefore, a relaxation of the self-selection constraint. This provides an incentive for the government in the South to implement higher marginal capital income tax rates for both ability-types than it would otherwise have done. (ii) An increase in the capital stock leads to a higher pre-tax wage rate for the low-ability type and, therefore, to increased factor income from the North. This provides an incentive for the government in the South to implement lower marginal capital income tax rates for both ability-types.

Propositions 3 and 4 describe two counteracting mechanisms via which outsourcing affects the income tax structure in the South. Note also that the size of the budget effect (discussed in the second part of each proposition) depends on the number of labor hours that the northern firms outsource to the South, $l_{n s, t}^{1}$. Therefore, the following result is an immediate consequence of Propositions 3 and 4;

Corollary 1. If the size of outsourced labor, $l_{n s, t}^{1}$, is small enough to imply

$$
\Lambda_{s, t} \frac{\partial l_{n s, t}^{1}}{\partial w_{s, t}^{1}}+l_{n s, t}^{1}<0,
$$


then the direct effects of outsourcing on the southern tax structure in period $t$ will be to decrease the marginal labor income tax rate for the lowability type, increase the marginal labor income tax rate for the highability type and increase the marginal capital income tax rates. If, on the other hand, $l_{n s, t}^{1}$ is large enough to imply

$$
\Lambda_{s, t} \frac{\partial l_{n s, t}^{1}}{\partial w_{s, t}^{1}}+l_{n s, t}^{1}>0,
$$

then the direct effect of outsourcing on the southern tax structure in period $t$ will be to increase the marginal labor income tax rate for the low-ability type, decrease the marginal labor income tax rate for the high-ability type and decrease the marginal capital income tax rates.

The corollary means that the qualitative policy response to outsourcing is related to the level of outsourcing. As long as the level of outsourcing is low, the government in the South will respond to outsourcing by increased labor income tax progression and higher marginal capital income tax rates, i.e., adjust the tax structure in the same qualitative way as the Northern government. However, if the level of outsourcing increases over time (if, e.g., the outsourcing cost of the North decreases over time for some reason), we may eventually reach a point where the government in the south responds by implementing a less progressive labor income tax and lower marginal capital income tax rates than it would have done, had outsourcing not been an option for firms in the North. In this case, where the level of outsourcing is relatively high, the optimal policy response by the southern government will be qualitatively the opposite from that of its northern counterpart.

\section{Policy Cooperation}

In Section 3, we analyzed a noncooperative Nash equilibrium, where each country implements its own tax policy and treats the tax policy decided upon by the other national government as exogenous. Since the policy implemented by either country affects the well-being of the residents in the other country as well, the noncooperative equilibrium is not efficient from the perspective of society as a whole. Therefore, policy cooperation (if designed appropriately) will lead to higher welfare. 
There are several possible approaches to address policy cooperation; the most common in earlier theoretical literature is probably to assume that the resource allocation is decided upon by a social planner, whose objective is to maximize welfare for society as a whole subject to all resources available. However, this approach is not particularly realistic from the perspective of real world public policy. It is, instead, much more realistic to assume that the countries agree upon reforms, the purposes of which are to improve the resource allocation by comparison with the initial equilibrium. We will follow the latter approach here by considering two policy reforms designed to target work hours and capital formation, respectively. In each such reform, the noncooperative Nash equilibrium is treated as the initial, prereform, equilibrium.

Suppose that policy cooperation is governed by a utilitarian objective

$$
W=W_{n}+W_{s}
$$

in which we give equal weight to the national welfare functions. By recalling that the noncooperative Nash equilibrium means that each national government has made an optimal policy choice conditional on the policies chosen by the other country, one can derive the following global welfare effects following changes in the hours of work;

$$
\begin{aligned}
& \frac{\partial W}{\partial l_{n, t}^{1}}=\frac{\partial W_{s}}{\partial l_{n, t}^{1}}=\gamma_{s, t}\left[\Lambda_{s, t} \frac{d l_{n s, t}^{1}}{d l_{n, t}^{1}}+\frac{\partial w_{s, t}^{1}}{\partial l_{n, t}^{1}} l_{n s, t}^{1}\right]<0 \\
& \frac{\partial W}{\partial l_{n, t}^{2}}=\frac{\partial W_{s}}{\partial l_{n, t}^{2}}=\gamma_{s, t}\left[\Lambda_{s, t} \frac{d l_{n s, t}^{1}}{d l_{n, t}^{2}}+\frac{\partial w_{s, t}^{1}}{\partial l_{n, t}^{2}} l_{n s, t}^{1}\right]>0 \\
& \frac{\partial W}{\partial l_{s, t}^{1}}=\frac{\partial W_{n}}{\partial l_{s, t}^{1}}=\gamma_{n, t}\left[\Lambda_{n, t} \frac{\partial l_{n s, t}^{1}}{\partial w_{s, t}^{1}}-l_{n s, t}^{1}\right] \frac{\partial w_{s, t}^{1}}{\partial l_{s, t}^{1}} \\
& \frac{\partial W}{\partial l_{s, t}^{2}}=\frac{\partial W_{n}}{\partial l_{s, t}^{2}}=\gamma_{n, t}\left[\Lambda_{n, t} \frac{\partial l_{n s, t}^{1}}{\partial w_{s, t}^{1}}-l_{n s, t}^{1}\right] \frac{\partial w_{s, t}^{1}}{\partial l_{s, t}^{2}} .
\end{aligned}
$$

The intuition behind equations (29) is straight forward. As each national government has already made an optimal choice of work hours at the national level via the labor 
income tax, a small increase in the hours of work does not affect the domestic welfare; it only affects welfare in the other country via the (uninternalized) externalities that outsourcing give rise to. The signs of equations (29a) and (29b) follow from assumption A1 in subsection 3.1. In addition, note that (by the Envelope Theorem)

$$
\frac{\partial W}{\partial c_{j, t}^{i}}=\frac{\partial W}{\partial x_{j, t}^{i}}=0 \text { for } i=1,2, \text { and } j=n, s,
$$

in the noncooperative Nash equilibrium, since private consumption does not give rise to international externalities. As a consequence, any change in private consumption induced by a change in the hours of work has no first order welfare effect.

Let us start with coordinated changes in the hours of work. With equations (28) and (29) at our disposal, it is straight forward to derive the following result;

Proposition 5. (i) Under assumption A1, a small decrease in the hours of work supplied by the northern low-ability type accompanied by a small increase in the hours of work supplied by the northern high-ability type leads to higher welfare in the South. (ii) If

$$
\Lambda_{n, t} \frac{\partial l_{n s, t}^{1}}{\partial w_{s, t}^{1}}-l_{n s, t}^{1}>0(<0),
$$

then a small decrease (increase) in the hours of work supplied by the southern low-ability type accompanied by a small increase (decrease) in the hours of hours work supplied by the southern high-ability type leads to higher welfare in the North.

Proposition 5 suggests that a coordinated change in the labor and capital income taxes can be designed to give higher welfare in both countries. The government is the North may implement the labor supply adjustment indicated by the first part of the proposition via increased marginal labor income taxation for the low-ability type and decreased marginal labor income taxation for the high-ability type, i.e. in a sense reduce the degree of labor tax progression, while at the same time changing the average labor income tax rates and the capital income tax in order to retain budget balance and adjust the capital stock to its original equilibrium path. For the government is the South, the problem is analogous, except that it should either increase the marginal labor income tax 
rate for the low-ability type and decrease it for the high-ability type, or decrease the marginal labor income tax rate for the low-ability type and increase it for the highability type, depending on whether $\Lambda_{n, t}\left(\partial l_{n s, t}^{1} / \partial w_{s, t}^{1}\right)-l_{n s, t}^{1}$ is positive or negative.

Finally, we analyze the welfare effects of a coordinated change in the capital stock. By differentiating equation (28) with respect to $K_{n, t}$ and $K_{s, t}$, respectively, and evaluating the resulting derivative in the noncooperative Nash equilibrium, we have (again by the Envelope Theorem)

$$
\begin{aligned}
& \frac{\partial W}{\partial K_{n, t}}=\frac{\partial W_{s}}{\partial K_{n, t}}=\gamma_{s, t}\left[\Lambda_{s, t} \frac{d l_{n s, t}^{1}}{d K_{n, t}}+\frac{\partial w_{s, t}^{1}}{\partial K_{n, t}} l_{n s, t}^{1}\right]>0 \\
& \frac{\partial W}{\partial K_{s, t}}=\frac{\partial W_{n}}{\partial K_{s, t}}=\gamma_{n, t}\left[\Lambda_{n, t} \frac{\partial l_{n s, t}^{1}}{\partial w_{s, t}^{1}}-l_{n s, t}^{1}\right] \frac{\partial w_{s, t}^{1}}{\partial K_{s, t}} .
\end{aligned}
$$

Equations (30a) and (30b) imply the following result;

Proposition 6. (i) Under assumption A1, a small increase in the northern capital stock leads to higher welfare in the South. (ii) If

$$
\Lambda_{n, t} \frac{\partial l_{n s, t}^{1}}{\partial w_{s, t}^{1}}-l_{n s, t}^{1}>0(<0),
$$

a small increase (decrease) in the southern capital stock leads to higher welfare in the North.

A coordinated policy reform with the effects presented in Proposition 6 also requires a combined change in the labor and capital income taxes. The government in the North may implement the first part of the proposition by decreasing the marginal capital income tax rates, while changing the average capital income tax rates and the labor income tax to retain budget balance as well as adjust the hours of work along the original equilibrium path. For the government in the South, the decision is analogous, except that it should either decrease or increase the marginal capital income tax rates depending on whether $\Lambda_{n, t}\left(\partial l_{n s, t}^{1} / \partial w_{s, t}^{1}\right)-l_{n s, t}^{1}$ is positive or negative. 


\section{Summary and Discussion}

Outsourcing has so far received surprisingly little attention in the literature on optimal income taxation. The present paper attempts to fill (part of) this gap by analyzing optimal labor income and capital income taxation in an OLG economy comprising two countries, where one of them (referred to as North) locates part of its low-skill production activities in the other (referred to as South). Each country is characterized by two ability-types and asymmetric information between the government and the private sector. Based on this framework, we analyze the tax policies implemented by each country in a noncooperative Nash equilibrium, where each national government treats the tax policy of the other country as exogenous, as well as policy coordination targeting the hours of work and capital formation, respectively.

Our results show that outsourcing by domestic firms provides an incentive for the government in the North to implement a lower marginal labor income tax rate for the low-ability type and a higher marginal labor income tax rate for the high-ability type, i.e. in this sense a more progressive labor income tax structure, and higher marginal capital income tax rates for both ability-types than it would otherwise have done. The intuition is that reduced outsourcing - a consequence of this policy response - leads to a more equal wage distribution in the North, which relaxes the self-selection constraint. In addition, reduced outsourcing contributes to lower the southern wage rate for lowskilled labor, meaning that less factor income is transferred to the southern economy. In the South, which receives foreign production structure and employment opportunities for its own labor force from abroad, outsourcing gives rise to two counteracting incentives. First, increased outsourcing leads to less wage inequality in the South, which constitutes an incentive for the southern government to implement a lower marginal labor income tax for the low-ability type, a higher marginal labor income tax rate for the high-ability type and higher marginal capital income tax rates for both ability-types than it would otherwise have done. The intuition is that these policy responses contribute to relax the self-selection constraint. Second, a decrease in the wage rate paid to lowskilled labor in the South also means less factor income from the North; a budget effect which calls for policy responses opposite to those just described. Therefore, the responses to outsourcing in terms of marginal income taxation by the southern 
government are, in general, ambiguous: if the level of outsourcing is sufficiently small (large), then the self-selection effect dominates (is dominated by) the budget effect in terms how the southern government responds to outsourcing.

With the noncooperative Nash equilibrium as our reference case, we also show that policy coordination leading to a decrease in the hours of work supplied by the northern low-ability type, an increase in the hours of work supplied by the northern high-ability type and an increase in the northern capital stock, respectively, is welfare improving for the South. The corresponding changes in work hours and capital formation that the South ought to implement depends on how the welfare in the northern economy changes in response to an increase in the wage rate paid to low-skilled labor in the South.

Future research might take several new directions, and we briefly discuss two of them. First, we have completely neglected the role of non-competitive wage formation. If the North is thought of as a European economy, it would clearly be relevant to allow trade-unions to affect wage formation for low-skilled workers and, as a consequence, allow for equilibrium unemployment among the low-skilled in the North. ${ }^{11}$ As tradeunions (most likely) attempt to push up the wage rate above the competitive level, there might be an even stronger incentive for firms in the North to outsource production capacity to the South. Therefore, non-competitive wage formation is important both for the public policy implemented by the national government and for the welfare effects of policy cooperation. Second, to be able to compare our results with those of the standard optimal income model, allowing us to capture the effects of outsourcing in the simplest possible way, we have disregarded other possible sources of interaction between the countries (e.g., factor mobility ${ }^{12}$ and final goods trade). Such an extension is clearly relevant here; for instance, labor mobility from the South to the North (due to higher wages in the North) may, to some extent, offset the incentives for outsourcing. It may

11 Such an extension may also include product market imperfections. There is a growing literature dealing with relationships between non-competitive wage formation, product market imperfections, globalization and outsourcing, although so far with a focus on issues other than redistribution via optimal income taxation. See, e.g., Naylor (1998, 1999), Lommerud et al. (2003) and Lommerud et al. (2009).

Aloi et al. (2009) have studied the effects of international integration of capital markets in the case when countries differ in their labor market institutions, i.e. one country has a perfectly competitive labor market while the other is unionized. But they have abstracted from considering unemployment in the country where labor market is unionized. 
also necessitate policy adjustments other than those described above. We leave these and other extensions for future research.

\section{Appendix}

\section{The North}

The first order conditions for $l_{n, t}^{1}, c_{n, t}^{1}, x_{n, t+1}^{1}, l_{n, t}^{2}, c_{n, t}^{2}, x_{n, t+1}^{2}$ and $K_{n, t+1}$, respectively, can be written as

$$
\begin{aligned}
& -\frac{\partial W_{n}}{\partial u_{n, t}^{1}} u_{n, t, z}^{1}+\lambda_{n, t} \hat{u}_{n, t, z}^{2}\left[\phi_{n, t}+l_{n, t}^{1} \frac{\partial \phi_{n, t}}{\partial l_{n, t}^{1}}\right]+\gamma_{n, t}\left[w_{n, t}^{1}-\frac{\partial w_{s, t}^{1}}{\partial l_{n, t}^{1}} l_{n s, t}^{1}+\Lambda_{n, t} \frac{d l_{n s, t}^{1}}{d l_{n, t}^{1}}\right]=0 \\
& \frac{\partial W_{n}}{\partial u_{n, t}^{1}} u_{n, t, c}^{1}-\lambda_{n, t} \hat{u}_{n, t, c}^{2}-\gamma_{n, t}=0 \\
& \frac{\partial W_{n}}{\partial u_{n, t}^{1}} u_{n, t, x}^{1}-\lambda_{n, t} \hat{u}_{n, t, x}^{2}-\gamma_{n, t+1}=0 \\
& -\left[\frac{\partial W_{n}}{\partial u_{n, t}^{2}}+\lambda_{n, t}\right] u_{n, t, z}^{2}+\lambda_{n, t} \hat{u}_{n, t, z}^{2} l_{n, t}^{1} \frac{\partial \phi_{n, t}}{\partial l_{n, t}^{2}}+\gamma_{n, t}\left[w_{n, t}^{2}-\frac{\partial w_{s, t}^{1}}{\partial l_{n, t}^{2}} l_{n s, t}^{1}+\Lambda_{n, t} \frac{d l_{n s, t}^{1}}{d l_{n, t}^{2}}\right]=0 \\
& {\left[\frac{\partial W_{n}}{\partial u_{n, t}^{2}}+\lambda_{n, t}\right] u_{n, t, c}^{2}-\gamma_{n, t}=0} \\
& {\left[\frac{\partial W_{n}}{\partial u_{n, t}^{2}}+\lambda_{n, t}\right] u_{n, t, x}^{2}-\gamma_{n, t+1}=0} \\
& \lambda_{n, t+1} \hat{u}_{n, t+1, z}^{2} l_{n, t+1}^{1} \frac{\partial \phi_{n, t+1}}{\partial K_{n, t+1}}+\gamma_{n, t+1}\left(1+r_{n, t+1}\right)-\gamma_{n, t}+\gamma_{n, t+1}\left[-\frac{\partial w_{s, t+1}^{1}}{\partial K_{n, t+1}} l_{n s, t+1}^{1}\right. \\
& \left.+\Lambda_{n, t+1} \frac{d l_{n s, t+1}^{1}}{d K_{n, t+1}}\right]=0
\end{aligned}
$$

To derive the marginal labor income tax rate for the low-ability type, combine equations (A1) and (A2) to 


$$
\begin{aligned}
& \frac{u_{n, t, x}^{1}}{u_{n, t, c}^{1}}\left[\lambda_{n, t} \hat{u}_{n, t, c}^{2}+\gamma_{n, t}\right] \\
& =\lambda_{n, t} \hat{u}_{n, t, z}^{2}\left[\phi_{n, t}+l_{n, t}^{1} \frac{\partial \phi_{n, t}}{\partial l_{n, t}^{1}}\right]+\gamma_{n, t}\left[w_{n, t}^{1}-\frac{\partial w_{s, t}^{1}}{\partial l_{n, t}^{1}} l_{n s, t}^{1}+\Lambda_{n, t} \frac{d l_{n s, t}^{1}}{d l_{n, t}^{1}}\right]
\end{aligned}
$$

By using $w_{n, t}^{1}-u_{n, t, z}^{1} / u_{n, t, c}^{1}=w_{n, t}^{1} T_{n, t}^{\prime}\left(w_{n, t}^{1} l_{n, t}^{1}\right)$ from equation (4), substituting into equation (A8) and rearranging, we obtain equation (20). The marginal labor income tax rate of the high-ability type can be derived in the same general way by combining equations (A4), (A5) and (4).

The marginal capital income tax rate of the low-ability type can be derived by combining equations (A2) and (A3), which gives

$$
\frac{u_{n, t, c}^{1}}{u_{n, t, x}^{1}}\left[\lambda_{n, t} \hat{u}_{n, t, x}^{2}+\gamma_{n, t+1}\right]=\lambda_{n, t} \hat{u}_{n, t, c}^{2}+\gamma_{n, t}
$$

Next, solve equation (A7) for $\gamma_{n, t}$ and substitute into equation (A9). Finally, by using $1+r_{n, t+1}-u_{n, t, c}^{1} / u_{n, t, x}^{1}=r_{n, t+1} \Phi_{n, t+1}^{\prime}\left(\kappa_{n, t}^{1} r_{n, t+1}\right)$, substituting into equation (A9) and rearranging, we obtain (22). The marginal capital income tax rate of the high-ability type can be derived in the same general way by combining equations (A5), (A6), (A7) and (5).

\section{The South}

The first order conditions for $l_{s, t}^{1}, c_{s, t}^{1}, x_{s, t+1}^{1}, l_{s, t}^{2}, c_{s, t}^{2}, x_{s, t+1}^{2}$ and $K_{s, t+1}$, respectively, can be written as

$$
\begin{gathered}
-\frac{\partial W_{s}}{\partial u_{s, t}^{1}} u_{s, t, z}^{1}+\lambda_{s, t} \hat{u}_{s, t, z}^{2}\left[\phi_{s, t}+l_{s, t}^{1} \frac{\partial \phi_{s, t}}{\partial l_{s, t}^{1}}\right]+\gamma_{s, t}\left[w_{s, t}^{1}+\frac{\partial w_{s, t}^{1}}{\partial l_{s, t}^{1}} l_{n s, t}^{1}\right. \\
\left.+\Lambda_{n, t} \frac{\partial l_{n s, t}^{1}}{\partial w_{s, t}^{1}} \frac{\partial w_{s, t}^{1}}{\partial l_{s, t}^{1}}\right]=0
\end{gathered}
$$




$$
\begin{aligned}
& \frac{\partial W_{s}}{\partial u_{s, t}^{1}} u_{s, t, c}^{1}-\lambda_{s, t} \hat{u}_{s, t, c}^{2}-\gamma_{s, t}=0 \\
& \frac{\partial W_{s}}{\partial u_{s, t}^{1}} u_{s, t, x}^{1}-\lambda_{s, t} \hat{u}_{s, t, x}^{2}-\gamma_{s, t+1}=0 \\
& -\left[\frac{\partial W_{s}}{\partial u_{s, t}^{2}}+\lambda_{s, t}\right] u_{s, t, z}^{2}+\lambda_{s, t} \hat{u}_{s, t, z}^{2} l_{s, t}^{1} \frac{\partial \phi_{s, t}}{\partial l_{s, t}^{2}}+\gamma_{s, t}\left[w_{s, t}^{2}+\frac{\partial w_{s, t}^{1}}{\partial l_{s, t}^{2}} l_{n s, t}^{1}\right. \\
& \left.+\Lambda_{n, t} \frac{\partial l_{n s, t}^{1}}{\partial w_{s, t}^{1}} \frac{\partial w_{s, t}^{1}}{\partial l_{s, t}^{1}}\right]=0 \\
& {\left[\frac{\partial W_{s}}{\partial u_{s, t}^{2}}+\lambda_{s, t}\right] u_{s, t, c}^{2}-\gamma_{s, t}=0} \\
& {\left[\frac{\partial W_{s}}{\partial u_{s, t}^{2}}+\lambda_{s, t}\right] u_{s, t, x}^{2}-\gamma_{s, t+1}=0} \\
& \lambda_{s, t+1} \hat{u}_{s, t+1, z}^{2} l_{s, t+1}^{1} \frac{\partial \phi_{s, t+1}}{\partial K_{s, t+1}}+\gamma_{s, t+1}\left(1+r_{s, t+1}\right)-\gamma_{s, t}+\gamma_{s, t+1}\left[-\frac{\partial w_{s, t+1}^{1}}{\partial K_{s, t+1}} l_{n s, t+1}^{1}\right. \\
& \left.+\Lambda_{s, t+1} \frac{\partial l_{n s, t+1}^{1}}{\partial w_{s, t+1}^{1}} \frac{\partial w_{s, t+1}^{1}}{\partial K_{s, t+1}}\right]=0
\end{aligned}
$$

The marginal labor income tax rates and marginal capital income tax rates can be derived in the same general way as they were derived for the North.

\section{References}

Acemoglu, D. and Zilibotti, F. (2001) Productivity Differences. Quarterly Journal of Economics 116, 563-606.

Aloi, M., Leite-Monteiro, M. and Lloyd-Braga, T. (2009) Unionized Labor Markets and Globalized Capital Markets. Journal of International Economics 78, 149-153.

Amiti, M. and Wei, S-J. (2005) Fear of Service Outsourcing: Is It Justified. Economic Policy 42, 307-347.

Aronsson, T. and Johansson-Stenman, O. (in press) Positional Concerns in an OLG Model: Optimal Labor and Capital Income Taxation. International Economic Review.

Aronsson, T. and Koskela, E. (2009a) Outsourcing and Optimal Nonlinear Taxation: A Note. Economics Letters 102, 135-137. 
Aronsson, T. and Koskela, E. (2009b) Optimal Redistributive Taxation and Provision of Public Input Goods in an Economy with Outsourcing and Unemployment. IZA Discussion Paper No. 4196, May, University of Bonn.

Aronsson, T. and Sjögren, T. (2004b) Efficient Taxation, Wage Bargaining and Policy Coordination.Journal of Public Economics 88, 2711-2725.

Aronsson, T., Sjögren, T. and Dalin, T. (2009) Optimal Taxation and Redistribution in an OLG Model with Unemployment. International Tax and Public Finance 16, 198-218.

Brett, C. (1997) A Note on Nonlinear Taxation in an Overlapping Generations Model. Department of Economics, University of Essex, mimeo.

Egger, H. and Egger, P. (2006) International Outsourcing and the Productivity of LowSkilled Labor in the EU. Economic Inquiry 44, 237-258.

Egger, H. and Falkinger, J. (2006): The Role of Public Infrastructure and Subsidies for Firm Location and International Outsourcing. European Economic Review 50, 1993-2015.

Ethier, W.J. (2005) Globalization, Globalisation: Trade, Technology and Wages. International Review of Economics and Finance 14, 237-258.

Feenstra, R.C. and Hanson, G.H. (1999) The Impact of Outsourcing and HighTechnology Capital on Wages. Quarterly Journal of Economics 114, 907-940.

Feenstra, R.C. and Hanson, G.H. (2003) Global Production Sharing and Rising Inequality: A Survey of Trade and Wages. NBER Working Paper No. 8372, published in: Kwan Choi, E. and J. Harrigan (2003) (eds): Handbook of International Trade, Blackwell Publishing Ltd, 146-185.

Geishecker, I. and Görg, H. (2005) Do Unskilled Workers Always Lose from Fragmentation?, North American Journal of Economics and Finance 16, 81-92.

Geishecker, I. and Görg, H. (2008) Winners and Losers: A Micro-Level Analysis of International Outsourcing and Wages. Canadian Journal of Economics 41, 243270.

Haskel, J. and Slaughter, M.J. (2001) Trade, Technology and U.K. Wage Inequality. Economic Journal 111, 163-187.

Hijzen, A. (2007) International Outsourcing, Technological Change, and Wage Inequality. Review of International Economics 15, 188-205.

Hijzen, A. Görg, H. and Hine, R.C. (2005) International Outsourcing and the Skill Structure of Labor Demand in the United Kingdom. Economic Journal 115, 860878.

Hsieh, C-T. and Woo, K.T. (2005) The Impact of Outsourcing to China on Hong Kong's Labor Market. American Economic Review 95, 1673-1687.

Hummels, D. Jun, I. and Yi, K.-M. (2001) The Nature and Growth of Vertical Specialization in World Trade. Journal of International Economics 54, 75-96. 
Keuschnigg, C. and Ribi, E. (2009) Outsourcing, Unemployment and Welfare. Journal of International Economics 78, 168-176.

Koskela, E. and Poutvaara, P. (2008a) Outsourcing and Labor Taxation in Dual Labor Markets, CESifo Working Paper No. 2333, June.

Koskela, E. and Poutvaara, P. (2008b) Flexible Outsourcing and the Impacts of Labour Taxation in European Welfare States, CESifo Working Paper No. 2440, October 2008.

Koskela, E. and Poutvaara, P. (2009) Is There Scope for Gains from Revenue-Neutral Labor Tax Reforms with Flexible Outsourcing? IZA Discussion Paper No. 3984, January, University of Bonn.

Koskela, E. and Schöb, R. (2008) Outsourcing of Unionized Firms and the Impact of Labour Market Policy Reforms. IZA Discussion Paper No. 3566, June, University of Bonn. Forthcoming in Review of International Economics.

Koskela, E. and Stenbacka, R. (2007) Equilibrium Unemployment with Outsourcing and Wage Solidarity under Labor Market Imperfections, CESifo Working paper No. 1988.

Lommerud, K.E., Meland, F. and Sorgand, I. (2003) Unionized Oligopoly, Trade Liberalization and Location Choice. Economic Journal 113, 782-800.

Lommerud, K.E., Meland, F. and Straume, O.R. (2009) Can Deunionization Lead to International Outsourcing? Journal of International Economics 77, 109-119.

Munch, J.R. and Skaksen, J.R. (2009) Specialization, Outsourcing and Wages. Review of World Economics 145, 57-73.

Naylor, R. (1998) International Trade and Economic Integration When Labor Markets are Generally Unionized. European Economic Review 42, 1251-1267.

Naylor, R, (1999) Union Wage Strategies and International Trade. Economic Journal 109, 102-125.

Ordover, J. E. and Phelps, E. S. (1979) The Concept of Optimal Taxation in the Overlapping Generations Model of Capital and Wealth. Journal of Public Economics 12, 1-26.

Pirttilä, J. and Tuomala, M. (2001) On Optimal Non-Linear Taxation and Public Good Provision in an Overlapping Generations Economy. Journal of Public Economics 79, 485-501.

Rishi, M. and Saxena, S. (2004) Is Outsourcing Really as Bad as it May Sound? Pittsburg University, working paper.

Sinn, H-W. (2007) The Welfare State and Forces of Globalization, CESifo Working Paper No 1925.

Stefanova, B.M. (2006) The Political Economy of Outsourcing in the European Union and the East-European Enlargement. Business and Politics 8, issue 2. 
Stern, N.H. (1982) Optimum Taxation with Errors in Administration. Journal of Public Economics 17, 181-211.

Stiglitz, J. E. (1982) Self-Selection and Pareto Efficient Taxation. Journal of Public Economics 17, 213-240.

Wilson, J.D. (1986) A Theory of Interregional Tax Competition. Journal of Urban Economics 21, 296-315.

Wilson, J.D. (1999) Theories on Tax Competition. National Tax Journal 52, 269-304. 